\title{
Legislative, Liability and Economic Strategies for Controlling Risks at Existing Hazardous Waste Facilities, and the Role and Use of Risk Assessment in a Preventive Program
}

\author{
by Richard C. Fortuna*
}

\section{Overview}

This paper will examine the evolution of the nation's basic authority that governs the daily management of hazardous waste, the Resource Conservation and Recovery Act (RCRA), its emphasis on preventive hazardous waste management, and its role in establishing a market for technologies that protect public health. The paper will examine the lessons learned from the implementation of RCRA's regulatory programs since its enactment in 1976 as well as other mechanisms to ensure proper waste management including: a strict liability standard, direct and indirect economic incentives, and corporate conscience. In addition, the role and ruse of risk assessment in a preventive program for existing hazardous waste management facilities will be examined.

The paper observes that both a formal regulatory system of structured Agency discretion to limit inherent regulatory uncertainties and a strict liability standard are essential to establishing a functioning marketplace of economic incentives to properly manage hazardous wastes. The success and significance of direct economic incentives and corporate conscience are predicated on the existence of a legislative and liability system that defines the market.

The risk assessment process is important to establishing national minimum performance standards for existing waste generators and/or treatment storage and disposal facilities. However, the risk assessment process is distinctly limited if not destructive when used to establish facility standards and/or definitions of "hazardous" waste that vary on a sitespecific basis. Moreover, caution must be used to ensure that the risk assessment process reveals, rather than disguises, the value and assumptions inherent in the process. Facilityspecific risk assessments may be useful to provide an additional level of protection when they are imposed by private insurers or by the facility itself, but not as a basis for establishing facility standards on a site-specific basis.

\footnotetext{
* Executive Director Hazardous Waste Treatment Council, before The Wharton School Conference on Risk Assessment and Risk Management Strategies for Hazardous Waste Storage and Disposal Problems. May 18,1988.
} 
The uncertainties and complexities of introducing facility-specific risk assessment into the RCRA program cannot be justified. Members of the industry would rather face the unpleasant than the uncertain. That is, engaging in a greater level of control than "necessary", in exchange for the certainty of knowing what standard must be met to ensure compliance and protection.

\section{Historical perspective on controlling current waste management practices}

Due to the central role of the Resource Conservation and Recovery Act (RCRA) and its regulatory programs as the risk management strategy established by the Congress for existing hazardous waste facilities, Sections II and III examine the historical evolution of the national hazardous waste program and RCRA's role as a cornerstone in establishing a market for preventive hazardous waste management, respectively.

\subsection{Humble beginnings (1976-1981)}

This fall will mark the thirteenth anniversary of the enactment of the Resource Conservation and Recovery Act (RCRA), the nation's basic authority for the preventive management of hazardous wastes. In 1976, the Congress gave EPA 18 months to promulgate all the necessary regulations to protect human health and the environment from exposure to hazardous wastes. The findings of the 1976 Act reflected a concern about the land disposal of hazardous wastes, but also emphasized a pending shortage of land disposal capacity as a major reason to develop alternatives to land disposal.

In 1980, RCRA was amended and May of that year saw the first major set of regulations issued, establishing interim status standards for treatment, storage, and disposal facilities. The expectation at that time on the part of many in the treatment industry, Congress, and the general public was that these standards would bring about better ways of managing hazardous wastes through the increased use of treatment, given that they were the first national standards for any hazardous waste facility. While it seemed like a good idea at the time, from the standpoint of treatment the promise of previous legislative endeavors has proved illusory and elusive. The regulations merely gave legal sanction to many loopholes or previously unregulated activities. They proved to be far less than stringent controls, and moreover proved the axiom that a statute present in name only is worse than no statute at all.

In 1982, the final regulations for land disposal facilities were issued along with final facility standards for surface impoundments. While being hailed as the remedy for all previous ills, the land disposal regulatory medicine may be worse than the disease, and provides more questions than answers.

From these brave but humble beginnings the national program of preventive hazardous waste management began to take shape. In retrospect it may be said that we in the Congress underestimated the scope and significance of the problem. At the time nobody, least of all those that were the crafters of the original legislation, believed that reversing the inertia of past land disposal practices and establishing a preventive program of hazardous waste management - one that did not propagate future Superfund sites - would turn out to be the environmental equivalent of balancing the federal budget. 


\subsection{Origins of the transition (1982-1984)}

By early 1982 the Gorsuch Team was firmly established at EPA. A fledgling and flawed program was coming under intense scrutiny, and if anything it was being strangled in the crib. Even some of the most fundamental and basic requirements, such as restricting the placement of containerized liquids into landfills, was being challenged as inappropriate, unnecessary, and too costly to industry. This might be because of the absence of any requirements for explicit cost consideration under RCRA.

It was against this background that Congress began the reauthorization process of 1982 which led to the most significant changes in any environmental law to date - a true watershed change to both RCRA as well as Congress' approach to environmental legislation in general. That era was filled with discoveries of other sites like Love Canal. A true dump of the month club was being assembled at an alarming pace, as well as repeated incidence of illegal dumping. It was this discovery of a new and seemingly endless stream of Superfund sites, many of which appear to be attributable to weaknesses in the program itself, that so accentuated the laissez faire policies of the Gorsuch era. The casual observer might assume a Congressional reaction such as reflected in the 1984 RCRA Reauthorization (i.e., the Hazardous and Solid Waste Amendments of 1984 (HSWA)) was attributable solely to political arrogance and a misguided philosophy.

For some this was no doubt the case. However, for those of us involved in rewriting the statute, the principle reaction to the Gorsuch era was the prompting of perhaps the most detailed and exhaustive examination of any environmental program to date. We quite literally took the program by its heels and shook it loose expecting to find nothing but political contraband falling to the floor. What we discovered is that just as many dentures hit the floor as did daggers. That is, the statute lacked many of the teeth necessary under any administration or political regime to promulgate a purposeful program aimed at prevention.

In short, the act itself had to share the blame along with the appointees. It was not so much "illegal dumping" that was creating new Superfund sites, but rather "legal dumping" occurring under the full sanction of the existing RCRA regulations. More waste generators and facilities were exempt from RCRA controls than were subject to it. The hole was quite literally bigger than the doughnut. Many wastes, including dioxins, were not listed as hazardous. Many recycling practices, such as placing wastes on roads to control dust (e.g., Times Beach, Missouri) were considered exempt recycling practices. During permitting, firms were increasingly engaged in "plume gerrymandering" and attempting to permit only the non-leaking units at their facilities while shifting the cleanup for leaking units to an already overburdened Superfund program. The gaps across the media coverage between water acts and the Clean Air Act were massive with inadequate controls on sewer disposal and/or evaporative emissions.

And last, but by no means least, there were no restrictions whatsoever on land disposal. Generators and disposers were free to land dispose any wastes they wished to.

Beyond the specific provisions and the land disposal bans and other requirements of the 1984 Amendments, the most fundamental change brought about by this enactment is to the decision making process itself. The 1984 RCRA amendments accomplish change in four specific ways by: establishing a national policy which states that land disposal is the method of last resort in the management of hazardous waste, RCRA Section 1004(b), 42 U.S.C. 6982(b); instituting presumptive prohibitions against land disposal of all untreated hazardous 
wastes, RCRA Section 3004(d), (e), (f), (g); avoiding a matching of specific waste management techniques to specific wastes and instead allow competing technologies to achieve a performance standard; and by supporting the presumptive prohibitions with the statutory set of minimum controls and self-implementing prohibitions (or hammers) in the event that EPA does not act to override or modify them by certain dates.

\subsection{Lessons learned}

The intervening years from 1976 to the present have been more instructive than constructive. They have yielded many valuable lessons on what will work and what won't in constructing a preventive hazardous waste management program. While this period was ostensibly dedicated to solving and/or preventing future hazardous wastes problems, in reality we have learned a great deal more about the nature and scope of the problem than we have implemented solutions to them. We have also learned about how the hazardous waste management industry functions, and moreover what makes it disfunction. By the end of 1984 we had a clear sense of the proper way in which to structure incentives/requirements to ensure both protective management of hazardous wastes, and to stimulate the emergence of a more responsible technology-based industry. In short, thirteen years of attempting to implement a preventive program through a system of statutory controls have provided us with the most meaningful possible lessons on the role of legislation in establishing demand for proper management, on the need to structure discretion to deal with inherent uncertainties of decision making in this field.

Agency discretion has become its worst enemy: too much of it is just as bad as too little. In the case of the hazardous waste program there had been too much discretion for too long a period of time. In a program that sorely needed leadership and appeared unable to choose among potential policy options, Congress was forced to substitute its judgment on a wide range of hazardous waste issues.

No administration, even one that is well intentioned, can cope with open ended discretion. An unlimited number of regulatory options leads to paralysis and maintenance of the status quo.

The 1980 regulations rather than increasing treatment, confidence, and certainty, merely redefined the loopholes due to their discretionary nature. The regulations themselves were proving to be the leading causes of our future Superfund sites with the firms furthest out on the limb being those that had invested in the best methods of management well in advance of the regulations.

"Legal dumping" was a more prominent threat to public health and to the certainty of investment and proper treatment than some more notorious counterpart "illegal dumping".

Methods exist to treat every waste that is currently begin generated (National Academy of Sciences, Committee on Disposal of Industrial Hazardous Waste, February, 1983). However, treatment methods will not be employed as long as there are so many legal ways to dispose of wastes that are not subject to control, when certain facilities are not required to meet public health standards, and when there are no qualitative or quantitative restrictions on land disposal to ensure that it is protective. (Wall Street Journal, 8/15/83, p.19). 
No matter how heroic the engineering effort there is a wide range of wastes that cannot be contained by land disposal facilities. As such, technical containment standards alone are a necessary though insufficient means of controlling the release of hazardous wastes from land disposal facilities. Public health policies must approach this problem from both directions: stringent facility containment standards, and waste treatment requirements or outright prohibitions on those hazardous wastes that cannot be contained by land disposal facilities.

Improper management has significant impacts beyond public health and natural resource concerns including economic development, property values, and property transactions.

\section{The role of legislation regulations in creating market demand for preventive and proper management}

There are few who would challenge the need for increased use of high-technology hazardous waste treatment. Moreover, based on the implementation of the 1984 RCRA Amendments, few could question whether such a transition is under way. This movement is premised on the belief that treatment, while not being magical in and of itself, when properly conducted provides certainty in two key respects: certainty in knowing what was done to the wastes, and certainty in knowing that future generations will not be exposed to their hazards. While these are compelling and self-evident benefits of treatment, there are equally telling reasons why treatment has not emerged to any significant degree.

The specific reasons for low cost unprotective land disposal are numerous: little capital is required up front; there are no inherent or technical limitations on what can be physically placed into a land disposal facility; many preventive measures such as dual liners and groundwater monitoring are either not required or avoided due to weak regulations and "grandfathering;" ultimate liability for the facility after closure may be shifted to governmental entities; and protection of public health is predicated solely upon physical barriers that cannot contain many wastes that are so disposed.

Just as the regulations in effect in 1982 and the inherent nature of the practice placed no restrictions on land disposal, a treatment facility invests the majority of its capital before a single load of waste is ever received. In addition, most forms of treatment operate under stringent standards governing process efficiency and duration, and are specific to certain waste streams. Unlike landfills, there is no current treatment process that can manage all types of wastes (i.e., incinerators must limit the concentration of metals in the waste feed, metal stabilization processes cannot accept high levels of solvents). Most importantly, it will always cost more to permanently render a waste non-hazardous at the time of generation under controlled conditions, than it will to simply bury and hope. The desire for increased certainty in the protection of public health cannot be separated from the inevitability of increased costs for proper hazardous waste treatment.

While treatment delivers greater certainty that wastes will be prevented from causing future threats to public health and the environment, certainty is a two way street. The regulations and policies must provide greater certainty that there will be a market for something other than unrestricted land disposal. Without an explicit policy that requires treatment as the primary method of waste management, the envisioned transition is little more than a pipe dream. As an article in the Wall Street Journal (8/15/83) observed, "There is a lot of 
risk involved in designing and siting a waste treatment plant. Why should a company take a technological risk along with other risks?" One might also query as to why a society that prides itself on high-tech innovations has had a no-tech approach to hazardous waste management?

In surveying the scope and expanse of the changes to the RCRA and Superfund hazardous waste management statutes to reverse this trend, one cannot help but to be struck by the proscriptive nature of these new legislative vehicles. Many in industry regard these changes as exceedingly unpleasant. However, it is important to place these concerns into a broader context in order to understand why a legislative/regulatory program is now and always will be the cornerstone of a preventive waste management program and the basis for establishing a market for protection.

Hazardous wastes are like water running down hill; they will always be disposed of along the path of least regulatory control and least cost. Market forces alone are an unreliable and indifferent broker when it comes to ensuring protective management of hazardous wastes in a cost competitive environment. The forces and facilities that establish the lowest marketplace cost also underwrite the methods which provide the least protection for public health and the environment when practiced without restriction.

The public, federal, and state regulators do not view the chemical industry or the hazardous waste industry as just another business. They do not see the industry as being in the business of simply managing hazardous waste, but rather as being in the business of environmental protection.

Prior to 1984 the hazardous waste regulations were structured as if the two fundamental facts of life did not apply to hazardous waste management: you get what you pay for, and there is no free lunch doing something always cost more than doing nothing.

Aside from these perceptions there is no avoiding the fact that management of hazardous waste is a "pay me now, pay me later" proposition. The only thing that changes is the form and amount of currency.

To a large extent, these proscriptive changes were inevitable. Many states already were beginning to implement land disposal bans. It is in the interest of all industries to have a nationally consistent scheme, rather than one that varies widely from one state to the next.

In addition, as the recipient of a disproportionate share of federal and state enforcement actions, the commercial hazardous waste management industry would rather face the unpleasant than the uncertain. It would rather face the unpleasant task of undergoing scheduled changes of facility operations, knowing that all competitors are doing the same, rather than having to do so sporadically based upon the individual state and federal agencies.

The treatment industry needs a level playing field. It could not allow a situation to persist where the land disposal was left largely unregulated, and where treatment methods such as incineration operated under stringent standards.

And last but not least, the commercial industry felt very strongly that it needed a national series of strict, minimal standards in order to close down a number of the flyby-night operators that have given this industry such a bad name, and that have caused untold liabilities to waste generators. 


\section{Other approaches to risk control: strict liability, economic, corporate conscience}

\subsection{Introduction}

In addition to the central role of legislation and regulations that establish the ground rules for preventive management at existing waste facilities, several other approaches have succeeded and are a necessary complement to ensure the viability of a legislative and regulatory system. These include: a system of strict liability for the cleanup of hazardous releases, other programs driven by cost and corporate value considerations (i.e., waste minimization, recovery, assets and liability evaluations), and corporate conscience. Waste managers and generators will control waste releases because they: have to, want to, are afraid not to, or believe they can save money doing so.

The "have to" part of this risk control equation was discussed above: regulations and legislation requiring national minimum standards, specific prohibitions on certain forms of waste management and sanctions for failing to comply. However, therein lies the weakness of regulations and legislation alone, they require enforcement. Enforcement is a discretionary activity that is only slightly less susceptible to changing political winds than a box kite. The incorporation of a joint, strict and several liability standard into the Superfund waste cleanup law has provided a necessary adjunct to the pre-1984 glacial pace of the regulatory programs and the unpredictable whims of the Agency enforcement. Firms now know that merely complying with a regulation may by itself not be a sufficient defense in the event that those regulations later prove to be inadequate. Nor is there safety in numbers. Waste generators and managers alike know that they alone may be singled out as the firm responsible for the cleanup of an entire site, irrespective of their proportional contribution to the site.

These two approaches to risk management taken together - legislation/regulations and a free standing joint, strict and several liability standard - are the indispensible elements that create the market for protective management. Either one alone is a necessary but not a sufficient means to ensure that decisions made in managing hazardous waste are also consistent with both short-term and long-term protection of public health and the environment. The other market incentive emerging from the implementation of this national scheme will be discussed below in further detail.

Partly as a result of RCRA's regulations and CERCLA's liability standard, and partly due to a desire to do the right thing, corporations are also moving toward risk prevention through frequent auditing systems to both anticipate and prevent releases of hazardous wastes. Lastly, perhaps the least quantifiable and most intangible of all the incentives for risk control are those that arise from the individual rather than the corporation. Included in this latter category are fear of what improper management can do to ones career, reputation or personal assets.

\subsection{Joint, strict and several liability standard}

In 1980 Congress enacted the Comprehensive Environmental Response, Compensation and Liability Act (CERCLA), commonly referred to as Superfund. Superfund has fundamentally reformed corporate liability for environmental releases by holding a company potentially liable for past activities, and by holding each party as potentially liable for the entire cost of cleanup-joint, strict and several liability. Under Superfund, any person 
that arranged for the disposal of "hazardous substances", any person who at the time of disposal owned or operated the facility, any person who selected a site and transported a hazardous substance there, and the present owner or operator of the site may be liable for all the cost of removal and long term remedial action at the site. Thus all parties in the chain of waste management may bear either some or individually bear all of the responsibility for cleanup including non-negligent past generator or current site operators even if there was no knowledge or fault with respect to past waste disposal.

Prior to the enactment of the 1984 Amendments, the "evolving" regulatory system rather than creating demand for proper management really gave comfort to the status quo. Those firms that had invested in permanent protective treatment technologies based on the expectations created by the 1980 RCRA regulations found themselves furthest out on a limb without a market to speak of. They continued to compete against low cost (i.e., in the short-term), unprotective land disposal methods. The impact of a regulatory system underwriting continued land disposal had its most dramatic impact on hazardous waste incineration. For example, until 1986/1987 the only appreciable market that existed for commercial incineration consisted of: polychlorinated biphenyls, which require incineration under TSCA regulation; the relatively few companies that believe that incineration was the proper way to manage wastes; and, a significant segment of companies that had unfortunately become involved as a potential responsible party in a Superfund action and sought to ensure that past practices were not repeated.

In short, the joint, strict and several liability standard under Superfund is now and will remain a leading incentive for changing corporate behavior and accounting for the liabilities of improper management through the use of preventive and protective waste management technologies. To the extent that this approach to environmental liability has been counterproductive in prompting cleanup of the sites themselves, the solution lies not with the liability standard, but with its execution. The seemingly endless negotiations and transactions at every phase of the cleanup process once parties have come forward has tended to overshadow the significance of the strict liability standard in achieving timely cleanups.

\subsection{Economic incentives}

The 1984 RCRA Amendments coupled with CERCLA's joint, strict and several liability standard have created a market for protecting public health and the environment. RCRA accomplished this end not by matching individual waste streams to specific technologies, but rather by eliminating the environmentally unacceptable practices that created Superfund sites in the first place, and by creating presumptions against on-going land disposal and other unprotective practices.

Unless waste management choices are governed by something other than simply lowest cost, unprotective practices that yielded short-term cost savings to the generator but that are potential long-term threats to the environment would not have changed. People who sought to invest in capital intensive operations needed to have a sense of certainty that the marketplace would not continue to simply perpetuate the status quo. With this program in place, coupled with the liability standards of Superfund, there is for the first time a reason for waste generators and managers to look at waste as something other than merely a discarded commodity, but rather as a resource and/or a social cost. However, unless and until these two cornerstones are in place no market would ever exist, except for those rare situations where a waste stream was either so valuable or concentrated as to warrant recovery. 
The economic underpinnings established by RCRA and Superfund have caused several private market mechanisms to account for past and potential environmental liabilities in the context of current assets and property transactions. A formal linkage between property transaction and accounting for past environmental liabilities has been incorporated into New Jersey law by the Environmental Cleanup and Responsibility Act (ECRA) [NJSA 13: 1K-6 et seq. (1981) - effective 1/6/82]. This law not only requires that at the time of a property transaction the owner reveal environmental liability associated with the site, but in addition engage in necessary cleanup actions to make it suitable for sale, and protective of public health and the environment. In addition, the financial community in general recognizes that accounting for environmental liabilities in their evaluation of assets, liabilities, corporate worth, or stock value may be the single most important facet of a transaction.

Another emerging market response to control environmental liabilities is witnessed in the growth of waste minimization efforts. Not until generators are faced with the true cost of waste management do they begin to look in earnest for ways to minimize the volume of "waste generated" and turn waste into a "resource", rather than a societal liability.

\subsection{Corporate conscience}

Another practice that can be directly linked to the growing stringency of RCRA and CERCLA's liability standard is the move by companies to conduct scheduled audits of waste operations to monitor practices and prevent releases and associated liabilities. Virtually every major company has an ongoing program of periodic audits of all of their waste management facilities to prevent waste releases and a future entanglement with Superfund liability or RCRA violation.

Beyond the national realm of regulatory agencies, Federal and state governments, and corporate behavior, is the individual. Prior to 1980 it was rare to see any individual that was held personally liable for the activities of the corporation. As the result of recent case law, this is changing. Personal accountability and fear for one's future career are becoming increasingly vital concerns. Many corporations have helped to affect and accelerate this level of consciousness by raising the level of decision making regarding the waste management to the level of the Board of Directors, rather than the sanitation department as has been traditional in many companies both large and small.

\section{The role and ruse of risk assessment in a preventive program}

The risk assessment process is one of the tools used in establishing control strategies for existing hazardous waste facilities. However, there are distinct limitations on the use of risk assessment in a preventive program. The RCRA program relies on implementability, consistency, timely decision making and prudent allocation of uncertainties. Risk assessment is being so over prescribed in the standard setting and waste definition processes that a potentially usefule antidote for uncertainty is being transformed into scientific snake oil.

The risk assessment process plays its most important role in establishing national minimum performance standards for wastes, facilities and generators under RCRA. Wastes are identified or listed as "hazardous" and facility standards developed based upon reasonable worse case scenarios; that is, what will happen if the waste/facility is not subject to the controls. On a national basis, the process is useful for assembling and arraying the assumptions, 
facts, as well as the judgments inherent in virtually every aspect of regulatory development: level of acceptable risk, type of statistic used, confidence interval used, fate and transport assumptions, exposure assumptions, etc. This process then yields a national minimum standard that has been subject to national scrutiny and that reflects the harms likely to result from mismanagement. There never will be universal agreement with any number or standard yielded by a regulatory process. Risk assessment can be used to establish national, uniform, minimum standards that clearly reveal the factors used to develop a standard, which then can be consistently applied.

Beyond these limited uses, the risk assessment can undermine the certainty that is necessary in the system: certainty in knowing what wastes are in the system, and what standards are that must be met. In recent months, the Agency has increasingly advocated the use of risk assessment to allow variances from the national minimum standards on a facilities-specific and/or site-specific basis. These variances are usually based upon assumptions about how different a facility may be from the national worst case scenario (i.e., population density, future land use, groundwater quality, attenuative properties of soil), and create significant environmental inequities, demands excessive use of resources and is an implementation nightmare.

By allowing generators and/or facility operators to either redefine what is "hazardous" for their situation or alter facility standards based upon site-specific considerations, we are establishing a policy that allows the following to occur: areas of lower population density are afforded less protection due to the alleged lower probability for exposure, areas of high contamination could be redefined as "non-hazardous" based upon assumptions about the unlikelihood of future land use, attenuative properties of the soil or, poor quality of the existing groundwater. It also assumes that the site-specific factors, which justify the variances, are somehow immutable, are never subject to human intervention, and that personal commitments will never be breached.

This approach also turns the purpose of RCRA on its head by focusing on exposure, rather than prevention of releases. Establishing different standards for each facility based upon site-specific assumptions changes and perverts RCRA's approach to waste management regulation from one that emphasizes preventing releases to one that maximizes the opportunity for exposures that are not assumed to be "harmful". The sordid history of this field has shown that wherever we have erred in the past it has always been on the side of inadequate controls, where the burdens and the uncertainties associated with such assumptions have fallen on those least capable of dealing with them.

From a broader perspective the risk assessment process does not reveal the answer, but rather is a subjective process that can yield many answers. The risk assessment process is being posited as the means to identify objective truth when indeed it is in many cases being abused in a manner that conceals, rather than reveals, the value judgments underlying such objectives. Assumptions are masquerading as surrogate facts. As the sitespecific variance example shows, the risk assessment process can be used to give a patina of credibility to public policies that are composed of little more than a particle board. We cannot avoid the fact that values and judgments are involved in these decisions not just data. The data rarely if ever speaks for itself, for which major public health decisions has ever been arbitrated by scientific data alone? All involve elements of uncertainty, controversy, and judgment. 
Rarely in this field do we ever act on pure scientific certainties, in fact in its pure sense environmental legislation is merely a means to allocate uncertainties and structure the discretion under which these uncertainties are allocated. Who bears the burden of proof? Who pays the price if the assumptions are wrong? To begin establishing standards for each facility/waste/locational combination not only misconstrues RCRA's statutory charge, but is an affront to practicality.

For current hazardous waste management facilities, the choice is not, What standard do we need to establish?, rather the question is always, What type of mistake do you want to make and on what side do you want to err? What better argument to err on the side of doing more to prevent mismanagement under the RCRA program than to look at Superfund. Once the wastes have been mismanaged and have escaped in the environment the panoply of imponderable never stops; Who contributed? How much? Who's contribution is more toxic? Who should pay? What should the clean-up level be? How should it be cleaned up? How are damages apportioned? The only way to prevent a continuing repetition of these questions is to put a maximum emphasis on preventing those situations that caused mismanagement and created Superfund sites, even if that means doing more than a given generator/facility believes necessary for their situation. Otherwise, rather than encouraging investment in prevention we will stimulate a foray for assumptions to redefine a waste/facility out of the system and to shift the emphasis of the program from prevention to self-servingly redefining pollution.

As the EPA itself observed in its now historic first series of hazardous waste regulations issued on May 19, 1980:

“The system may not work perfectly for every waste however. It may over regulate in some instances and under regulate in others. This is an unavoidable consequence of attempting to develop a national hazardous waste management program which has to regulate thousands of wastes into hundreds and thousands of individual transportation, treatment storage and disposal situations. To develop a program which would provide precisely the right degree of environmental and health protection in each management situation would require regulations which would be either so vague that they would offer limited guidance to the regulated community and would be largely enforceable or so extensive and so encumbered with provisions for case-by-case variance that they would be an administrative nightmare for both EPA and the hundreds and thousands of persons and facilities which are potentially subject to them period."

Unless restrained, the risk assessment process rather than providing a noticeable improvement to regulatory standard setting, will become the nightmare the Agency foresaw over eight years ago: a way to encourage people to redefine and dissemble, rather than prevent and comply.

\section{REFERENCES}

FORTUNA, R., and LENNET, D., "Hazardous Waste Regulations: The New Era," McGraw Hill, 1987

HALL, R., and CASE, D., “All About Environmental Auditing” Federal Publications Inc., Washington, DC, 1987

Current Practices in Environmental Auditing, Report to the U.S. Environmental Protection Agency, Arthur D. Little Inc., February 1984 